\title{
El registro de deudores en el concurso de la persona natural como elemento restrictivo del alivio del deudor
}

\author{
Miguel Ángel Alarcón Cañuta*
}

RESUMEN

El presente estudio plantea un análisis crítico de las consecuencias que el tratamiento de la información relativa al concurso, incorporada en registros de deudores, presenta para el deudor persona natural en el contexto nacional, y propone reflexiones para una armonización de la normativa y un reequilibrio de los intereses de protección del acreedor que evalúa el riesgo financiero del consumidor y el interés de alivio del futuro deudor.

Registro de deudores; efectivo alivio; registro de solvencia positivo

\section{The debtor's register in the bankruptcy of the natural person as a restrictive element of the debtor's relief}

\begin{abstract}
This study proposes a critical analysis of the consequences that the treatment of the information related to the bankruptcy procedure, incorporated in debtor registers, presents for the natural person debtor in the national context, and proposes reflections for a harmonization of the regulations and a rebalancing of the creditor's protection interests that assesses the financial risk of the consumer and the relief interest of the future debtor.
\end{abstract}

Debtor's register; effective relief; positive solvency register

* Licenciado en Ciencias Jurídicas, Universidad Católica de Temuco, Máster en Derecho con especialidad en Derecho Privado, Universidad de Barcelona, España. Doctor en Derecho, Universidad de Barcelona, España. Profesor Asociado de la Carrera de Derecho, Facultad de Ciencias Jurídicas y Políticas, Universidad Arturo Prat. ORCID: https://orcid.org/0000-0002-3284-0966 Correo electrónico: maac23@gmail.com Artículo recibido el 2.2.2021 y aceptado para su publicación el 8.7.2021. 


\section{INTRODUCCIÓN}

nivel nacional como en el ámbito comparado, las legislaciones concursales
contemplan exigencias de mantenimiento de registros con información relativa
al concurso del deudor. Desde el punto de vista del prestamista, ello permite una mejor valoración de las aptitudes del deudor para asumir una futura obligación ${ }^{1}$.

Un registro concursal de deudores está integrado por información almacenada en una base de datos pública o privada relativa al procedimiento concursal del que es o fue parte una persona deudora, del que es posible extraer datos como identidad del deudor, fecha de inicio y tipo de procedimiento (liquidación o renegociación), descarga de la deuda residual, deudas exceptuadas de la descarga, entre otros.

Ahora bien, en el contexto del concurso de la persona natural, y aplicado al deudor cuya naturaleza jurídica es la de persona natural ${ }^{2}$, efectivo alivio se entiende como el retorno del deudor a las circunstancias o estado de cosas que le permiten volver a ostentar la capacidad para desarrollar libremente su personalidad y lograr el desarrollo de su familia $^{3}$, y en términos económicos, reinsertarse en la vida económica ${ }^{4}$.

Uno de los elementos del concurso que posibilita tal finalidad es el tiempo que media entre el inicio del procedimiento y el momento en que el deudor obtiene la extinción de los saldos insolutos (descarga), que teóricamente marca el punto en el que el deudor es rehabilitado y hace posible el logro de un nuevo comienzo 5 . Desde esta comprensión, se requiere un procedimiento expedito, de duración estrictamente necesaria para el logro de su objetivo, cuestión que se vincula, entre otros, con el registro de información del deudor relativa al concurso, por un tiempo determinado, durante o con posterioridad al procedimiento.

En este trabajo abordaremos este último punto, bajo la hipótesis de que el mantenimiento de información del deudor relativa al concurso restringe su interés de obtener un efectivo alivio tras el procedimiento concursal. El objetivo es plantear un análisis crítico de las consecuencias que el tratamiento de información relativa al concurso, incorporada en registros de deudores, presenta para el deudor persona natural en el contexto nacional, y proponer reflexiones que permitan una armonización de la normativa en torno a un necesario equilibrio entre los intereses de protección del futuro acreedor que evalúa el riesgo crediticio del consumidor y el interés de alivio del futuro deudor. Para ello, en el apartado II. se analiza el estado actual del tratamiento que el ordenamiento nacional efectúa de la información concursal del deudor y su utilización por los acreedores de cara a la concesión de crédito; en los apartados III. y IV., tras una aproximación a la

${ }^{1}$ Miller, 2000, p. 2; Turner y Varghese, 2010, pp. 6 y 7; Ferretti, 2013, p. 794 . Art. 14 inciso 2 del DFL 3, 1997, que refunde la Ley General de Bancos (LGB).

${ }^{2}$ Aunque nuestro modelo considera empresa deudora a ciertas personas naturales, ello no obsta a que su naturaleza jurídica se mantenga.

3 Alarcón, 2021a, pp. 319 y 338.

${ }^{4}$ Howard, 1987, p. 1069.

5 Alarcón, 2018, p. 14; Caballero, 2018, p. 134. 
experiencia española y alemana en la materia, se plantea una valoración crítica de las consecuencias que el tratamiento presenta en el interés del deudor de lograr un alivio; finalmente, en el apartado V., se ofrecen reflexiones para una armonización de la normativa en consideración a una herramienta que fomenta el resguardo del futuro acreedor que evalúa el riesgo crediticio del consumidor y el interés de alivio del futuro deudor.

\section{LAS ANOTACIONES DE DEUDORES EN EL ORDENAMIENTO NACIONAL}

1. ¿Un registro de deudores tácito en la Ley 20.720?

El art. 6 inciso final de la Ley 20.720 de reorganización y liquidación de empresas y personas (LRLEP) ${ }^{6}$ establece que una vez finalizados los procedimientos concursales, la Superintendencia de Insolvencia y Reemprendimiento (SIR) deberá proceder a la eliminación, modificación o bloqueo de los datos del deudor en el Boletín Concursal (BC) de acuerdo con la Ley de Protección de la Vida Privada (LPVP) ${ }^{7}$.

El mantenimiento de todo antecedente del concurso ${ }^{8}$ en el $\mathrm{BC}$ se fundamenta en la necesidad de publicidad de las actuaciones para su conocimiento por parte de los acreedores actuales o eventuales ${ }^{9}$, con el consecuente fomento de la par condicio creditorum ${ }^{10}$.

El art. 6 LPVP establece que cualquier registro deberá ser eliminado cuando no exista fundamento legal o cuando haya caducado. Concluido el procedimiento concursal, no se justifica que los antecedentes del concurso se mantengan visibles en el BC, pues el fundamento para su mantenimiento expira con la resolución de término del procedimiento ${ }^{11}$. A pesar de ello, el BC actúa como registro público de personas sometidas a un procedimiento concursal y da a conocer sus resultados mientras no se encuentre firme la resolución de término del procedimiento de renegociación o liquidación ${ }^{12}$.

En este contexto, la LPVP permite la utilización de datos personales para fines distintos para los que fueron recolectados cuando sean extraídos de fuentes accesibles

${ }^{6}$ Ley $20.720,2014$.

${ }^{7}$ Ley $19.628,1999$.

8 Art. 4, Norma de Carácter General No 3 (NCG) de la SIR.

${ }^{9}$ Ello puede colegirse del art. 2 No 7 de la Ley 20.720. Así también, BAEZA, 2013, p. 1297.

${ }^{10}$ Sobre la publicidad de los procedimientos, Leturia, 2018, p. 649, expresa que estructuralmente beneficia a todas las personas que puedan participar de un proceso o verse afectados por su desarrollo.

${ }^{11} \mathrm{La}$ Superintendenta de Insolvencia y Reemprendimiento, en Informe de Comisión de Constitución, Historia de la Ley 20.720, p. 1988, expresó que "el derecho de uso y la finalidad del dato no estarán limitados durante los procedimientos concursales, por cuanto la información que se publica en el Boletín Concursal será de acceso público".

12 Así, art. 10 e), NCG SIR. 
al público ${ }^{13}$, carácter que por definición legal cumple el BC. Sin embargo, no establece qué otros fines podrán ser buscados con la utilización de estos datos ${ }^{14}$.

Desde el punto de vista del interés del deudor de volver a ser miembro activo de la sociedad con posterioridad al concurso, el art. 9 inciso 3 LPVP prohíbe evaluaciones de riesgo comercial que no estén basadas en información objetiva relativa a morosidades o protestos de las personas naturales de las cuales se informa. Sin embargo, es criticable que la ley no contenga una sanción disuasoria (como sería una multa elevada) para el caso en que la institución incumpla esta prohibición, donde el resguardo de los intereses del deudor se deja solo a él, porque al titular de los datos solo le asiste una facultad para solicitar su eliminación y demandar indemnización de perjuicios ${ }^{15}$. Además, si bien la norma prohíbe evaluaciones no basadas en información objetiva respecto de morosidades o protestos de las personas "de las que se informe", nada señala respecto de los datos obtenidos a partir de su libre recolección en registros públicos, y no informados por entes públicos o privados.

La facilidad con que datos del deudor pueden ser recolectados, utilizados y transferidos a partir del BC, complementada con un vacío legal en materia de utilización de esta información, posibilita que bancos e instituciones financieras mantengan y transfieran información del deudor sin limitación, que puede ser usada para "caracterizarle" a efectos de otorgar o no un producto financiero ${ }^{16}$.

Podría estimarse que los arts. 18 inciso 2 y 19 inciso 3 LPVP favorecen la protección de la información concursal del deudor. Las normas respectivamente prohíben comunicar datos relativos a deudas de carácter económico, financiero, bancario o comercial que señala el art. 17, después de haber sido pagadas o haberse extinguido por otro modo legal, y obligan al responsable del tratamiento de los datos obtenidos de fuentes de acceso público a modificarlos en el mismo sentido tan pronto comunique aquella el pago o la extinción, o en el plazo de tres días. Con ello, tanto las obligaciones cubiertas durante el procedimiento concursal (extintas mediante el pago), como los saldos no cubiertos y extintos por la descarga de la deuda, no deben ser comunicados a instituciones públicas o privadas y deberían ser modificadas o eliminadas al estar extintas. No obstante, lo cierto es que la información obtenida del BC dice relación con el hecho mismo de haber sido el deudor insolvente y parte en un concurso, y como se verá, la información relativa a las deudas puede igualmente ser comunicada con posterioridad a la descarga.

13 Art. 9 LPVP.

${ }^{14}$ El respeto del principio de finalidad del tratamiento de datos (art. 1 Ley 20.575, 2012), esto es, la evaluación de riesgo comercial y para el proceso de crédito, solo es exigido para el tratamiento de información relativa a deudas comerciales del art. 17 LPVP. Así, Alvarado, 2014, pp. 218.

15 De igual forma, Álvarez, 2016, p. 65.

${ }^{16}$ Sobre los efectos contraproducentes de los datos obtenidos de fuentes accesibles al público, ALVARADO, 2014, pp. 218 y 219. 


\section{Casos fallados por la jurisprudencia}

La jurisprudencia nacional analizó el caso en el que instituciones bancarias rechazan la solicitud de un producto financiero de un consumidor con justificación en la existencia de una deuda previa encontrada en determinados registros. La nota común de los casos radica en que la pretensión del consumidor viene dada por vía de acción de protección, y que la deuda registrada era parte del pasivo en un procedimiento concursal de liquidación, respecto de la que había operado la extinción o descarga del art. 255 LRLEP.

En un caso, la Corte de Apelaciones de Temuco estima que es la entidad bancaria la que mantiene registros paralelos de morosidad ${ }^{17}$ que no se encuentran vigentes, vulnerando el principio de rehabilitación del deudor sometido al proceso de liquidación voluntaria ${ }^{18}$.

Destaca que se trata de una acción constitucional ante una situación que transgrede el derecho a la honra de la persona, en la medida que la consideración de una situación de desajuste económico financiero en el patrimonio de la persona natural, que si bien no necesariamente se condice con una insolvencia, le caracteriza de manera errónea a efectos del otorgamiento del producto financiero.

Debe notarse que la negativa al otorgamiento del producto financiero por el banco no considera una eventual situación de insolvencia del consumidor, sino la sola existencia de una deuda. Si bien es debatible que una deuda sea motivo para limitar la contratación con un consumidor que no necesariamente es insolvente desde una adecuada evaluación de la solvencia por el prestamista ${ }^{19}$, interesa remarcar la facilidad con que es posible crear un registro paralelo de deudores por el prestamista con información que no se condice con la realidad, al contener datos que no son actuales, y respecto de deudas previamente extintas.

En un segundo caso $^{20}$, el banco alega que utilizó un registro emanado de la Superintendencia de Bancos e Instituciones Financieras (SBIF), que contenía la deuda que posibilitó el rechazo del producto financiero, previamente descargada. Para una mejor comprensión, en uso de las facultades que le otorga el art 14 de la Ley General de Bancos (LGB), la Comisión para el Mercado Financiero (CMF) consolida y entrega información relativa a deudas comerciales de los consumidores a bancos e instituciones financieras.

El art. 1 LPVP hace aplicables sus disposiciones a instituciones públicas como privadas, siempre que efectúen un tratamiento de datos de carácter personal, entendiéndose por ello cualquier operación o complejo de operaciones o procedimientos técnicos, automatizados o no, que permitan recolectar, almacenar, organizar, comunicar o transmitir

${ }^{17}$ Corte de Apelaciones de Temuco, 04.05.2018, rol 1.356-2018, considerando noveno; confirmada por Sentencia de la Corte Suprema, 30.05.2018, rol 8.779-2018.

${ }^{18}$ Corte de Apelaciones de Temuco, 04.05.2018, rol 1.356-2018, considerando décimo.

${ }^{19}$ Respecto de la evaluación de la solvencia por parte del prestamista, GoldenBerg, 2020, pp. 14 a 16; Alarcón, 2021c, en prensa.

${ }^{20}$ Corte Suprema, 17.12.2018, rol 15.516-2018. 
datos de carácter personal, o utilizarlos en cualquier forma ${ }^{21}$. Como órgano público, la SBIF (actual CMF) está sometida a la LPVP, especialmente al art. 6, que obliga a eliminar o cancelar datos cuando su almacenamiento carezca de fundamento legal o hayan caducado, esto es, cuando pierden actualidad por disposición de la ley o por el cambio de los hechos o circunstancias que consigna, como sucede en el caso en que opera la descarga de la deuda respecto de una obligación determinada. De igual forma, le es aplicable el art. 9, que exige exactitud, actualización y veracidad en la información tratada.

Establecido lo anterior, si bien según el punto 5 del Capítulo 18-5 de la Recopilación Actualizada de Normas de la SBIF (RAN) podría existir responsabilidad para el que entrega información sobre deudas no pagadas que no se ajuste a la entera y clara verdad, y a pesar de que en el párrafo segundo la Superintendencia se exime de responsabilidad declarando que solo efectúa una refundición de los datos que le son entregados ${ }^{22}$, lo cierto es que al recopilar, organizar y comunicar la información que le entregan las instituciones fiscalizadas incurre en tratamiento de información incorrecta cuando en los registros se contienen deudas extintas. La crítica también es extensiva a los bancos e instituciones financieras, que entregan la información de sus deudores a la Superintendencia para su tratamiento.

El considerando décimo de la sentencia plantea que

"En estas circunstancias en que, atendido el término del procedimiento de liquidación la condición de deudor del recurrente no se encontraba, a la fecha en que solicitó la apertura de la cuenta corriente al recurrido, "establecida de un modo formalmente incuestionable” -como exige el capítulo 18-5 [RAN]-procedía que la información cuestionada fuera excluida o al menos suspendida de dicho registro. Ello por cuanto al tenor del artículo 6 [LPVP] el dato en cuestión adquirió al menos la categoría de dudoso".

Sin embargo, aunque la LPVP faculta a la persona del consumidor, antiguo deudor, para solicitar la eliminación de información caduca, ni tal ley ni la LGB contemplan mecanismos que obliguen coactivamente a la CMF o a las instituciones bancarias o financieras a respetar la obligación de eliminar de sus registros datos no verídicos o caducos ${ }^{23}$.

21 Art. 2 o), LPVP.

${ }^{22}$ Apartado 5, párrafo segundo, Capítulo 18-5 RAN.

${ }^{23}$ Solo si la persona reclama y la institución retarda la eliminación de los datos ordenada por el tribunal el art. 16 LPVP establece una multa de 1 a 50 UTM, manifiestamente baja. Álvarez, 2016, p. 53, critica la falta de utilización del procedimiento por lo largo y costoso, y en pp. 56 ss. da cuenta de doctrina partidaria por una regulación que cuente con un órgano autónomo que fiscalice y sancione conductas atentatorias a la ley. 


\section{EL REGISTRO DE DEUDORES CONCURSALES EN ORDENAMIENTOS COMPARADOS}

A continuación se da a conocer brevemente la experiencia española y alemana de registro de información concursal del deudor, que por las diferencias que presentan entre sí, permiten establecer ciertas bases comparativas que permitirán, en el apartado siguiente, valorar críticamente las consecuencias que el tratamiento de cierta información presenta para el interés del deudor de lograr un alivio.

\section{Las anotaciones de exoneración de la deuda en el modelo español}

Como uno de los requisitos para apreciar la buena fe del deudor de cara a la obtención de una descarga del pasivo insatisfecho en la forma de exoneración aplazada mediante un plan de pagos, el antiguo art. 178 bis.3.5 ${ }^{\circ}$.v) Ley Concursal española (LC) ordenaba la aceptación expresa del deudor de que la obtención de la descarga se haría constar en una sección especial del Registro Público Concursal por el plazo de cinco años. La anotación permanecería por el plazo de cinco años posteriores a la concesión definitiva de la descarga de la deuda en virtud del párrafo primero del artículo 178 bis.8 LC. El actual art. 499.3 del Texto Refundido de la Ley Concursal (TRLC), aunque establece que la exoneración definitiva otorgada al deudor en la forma aplazada será inscrita en el Registro Público Concursal, no establece plazo máximo para la inscripción.

El antiguo art. 178 bis LC permitía interpretar que los requisitos para la exoneración eran copulativos a las formas contempladas en la ley, con lo que la exigencia planteada era aplicable tanto para la exoneración directa sin plan de pagos como para la forma aplazada por medio del plan de pagos ${ }^{24}$. El TRLC actual no contempla, ni como requisito de acceso, ni como efecto de la descarga, la inscripción de su otorgamiento en el Registro de Público Concursal para el caso de que el deudor pueda acogerse a la forma directa de exoneración contemplada de los arts. 487 al 492 TRLC.

Es criticable que la norma establezca la exigencia solo para deudores que han obtenido la descarga de manera aplazada y luego de haber pasado por un periodo de buena conducta $^{25}$, cuando la única diferencia con la forma directa es que en esta el deudor ha pagado un porcentaje mínimo a sus acreedores para obtener la descarga. Además, el texto vigente no establece un periodo máximo en el que la información de los deudores permanecerá en el Registro Público Concursal. Ello implica un grado importante de incertidumbre jurídica para deudores personas naturales que, de cara a las pretensiones de reactivar su vida económica con posterioridad a la obtención de la exoneración, no pueden optar por la forma directa, que el TRLC considera régimen general.

${ }^{24}$ Entendiendo que la exigencia es aplicada solo al caso de exoneración por un plan de pagos, PULGAR, 2015; Cuena, 2016, pp. 118 y 119.

25 Sobre el plan de pagos como periodo de buena conducta, Alarcón, 2020, pp. 187 a 190. 
La justificación que tuvo el legislador español para establecer el requisito de inscripción de la exoneración es la protección de los intereses de los acreedores. Ello se comprende a partir de la exposición de motivos de la antigua LC y la historia de la ley en torno a la introducción de la descarga en el ordenamiento español ${ }^{26}$. Como expresaba la antigua norma del art. 178 bis. $3.5^{\circ}$.v) LC, únicamente tendrían acceso a esta información las personas que tuvieran interés legítimo en averiguar la situación del deudor, entendiéndose que tienen interés "quienes realicen una oferta en firme al deudor ya sea de un crédito o de cualquier otra entrega de bienes o prestación de servicios, que tenga que ser remunerada o devuelta por este y que esté condicionada a su solvencia”.

\section{Las anotaciones de denegación y revocación de la descarga en el modelo alemán}

Mediante la $§ 303$ a, la reforma de la InsO de 2014 estableció que la denegación o revocación del alivio de la deuda será incluido en los sistemas de información de créditos de la Schutzgemeinschaft für allgemeine Kreditsicherung (SCHUFA) ${ }^{27}$. El registro mantiene por un periodo de tres años la información relativa a una denegación o revocación del alivio de la deuda respecto de un deudor que ha sido parte en un procedimiento concursal ${ }^{28}$.

El fundamento considerado por el legislador alemán para instaurar el registro fue la protección del interés de los acreedores, bajo el entendido de que por medio del conocimiento de la denegación o revocación del alivio de la deuda, podrían efectuar una más adecuada evaluación de la solvencia crediticia a la hora de otorgar crédito ${ }^{29}$.

En la redacción del proyecto original se ha planteado que existía la idea de que debido a que el riesgo de recurrencia en la insolvencia se encuentra sobre todo respecto de deudores deshonestos que buscan obtener préstamos que luego no pueden o no quieren pagar, los redactores del proyecto habrían asumido que todo deudor es típicamente deshonesto $^{30}$; razón que habría justificado acciones para proteger los intereses de los futuros acreedores. Luego, entendiéndose que el procedimiento debe otorgar alivio a todo deudor honesto ${ }^{31}$, la perspectiva descrita presentaba una contradicción con los objetivos originalmente considerados por el legislador a la hora de implementar la reforma del procedimiento concursal de la persona física en $2014^{32}$.

La contradicción entre los objetivos idealmente planteados por el legislador y la regulación finalmente lograda con la $\S 303$ a InsO se presenta además respecto de la pretendida disminución del tiempo para un alivio. Así, se ha criticado que si el legislador pretendió promover el emprendimiento mediante la disminución del tiempo de

${ }^{26}$ Exposición de Motivos de la LC, II, párrafo tres, p. 6; Intervención del Ministro de Economía y Competitividad en Discusión en Sesión de Convalidación o Denegación del RDL 1/2015, cit., p. 17.

27 Proyecto de Ley de Reforma de la InsO de 2012, BT-Drucks. 17/11268, p. 33.

${ }^{28}$ Hofmeister, 2014, p. 251; SCHMERBACH, 2012, p. 58.

29 BT-Drucks. 17/11268, p. 33. En tal contexto, SCHmerbach, 2012, p. 58.

30 BECK, 2012, p. 230.

31 BT-Drucks. 17/11268, p. 1.

32 Pape, 2012, p. 153; BeCK, 2012, p. 230. 
duración de los procedimientos concursales de la persona natural para devolverla más rápidamente a una situación de vida digna ${ }^{33}$, ello no se logra en la práctica, porque un efectivo alivio de la deuda no llega sino hasta pasados tres años posteriores al término del procedimiento concursal ${ }^{34}$.

\section{LA PRIVACIÓN DE UN EFECTIVO ALIVIO PARA EL DEUDOR}

Más allá del objetivo de proteger los intereses de los acreedores, en la práctica, el registro concursal de deudores adquiere una connotación negativa ${ }^{35}$. Debido a que el procedimiento concursal se califica como una consecuencia del problema de la insolven$\mathrm{cia}^{36}$, se aprecia al deudor como una persona potencialmente riesgosa, a pesar de cumplir sus obligaciones y ser beneficiado con una descarga de la deuda ${ }^{37}$. Ello se constituye en una discriminación arbitraria ${ }^{38}$ que, repercutiendo negativamente en sus pretensiones de obtención de crédito, significa una limitación de sus posibilidades de vida digna ${ }^{39}$.

Si bien podría estimarse que la necesidad de registrar antecedentes de un procedimiento concursal o su resultado se justifica en la consideración de que una limitación al principio de responsabilidad patrimonial universal debe ir acompañado de un mayor flujo de información financiera del deudor, lo que fomenta la competencia financiera para ofrecer mejores tipos de interés a los clientes ${ }^{40}$ y supone un control del sobreendeudamiento de los particulares ${ }^{41}$, la experiencia comparada permite criticar el plazo, contenido y forma del registro establecido en nuestra legislación.

El plazo de cinco años que establecía la antigua LC española parecía excesivamente largo en comparación a los tres años que contempla el procedimiento alemán, en el que, aún con tal extensión, fue criticada la consecuencia desfavorable que la anotación de la descarga en un registro conllevaba para las pretensiones de alivio del deudor. Desde esta consideración, la incertidumbre jurídica que entrega el modelo nacional, que no establece un plazo máximo en el que permanecerá la información del deudor en los registros ${ }^{42}$, se equipara a la actual regulación del TRLC español. En este contexto, tanto el Reglamento europeo de protección de las personas físicas en lo que respecta al tratamiento de datos

33 BT-DruCKs. 17/11268, p. 1.

${ }^{34}$ PApe, 2012, pp. 153 y 154. Dando ejemplos, BeCK, 2012, p. 226 y PAPE, 2012, pp. 153 y 154.

${ }^{35}$ Henning, 2014b, p. 222.

36 Hofmeister, 2014, p. 251.

37 PAPE, 2012, p. 154.

38 Henning, 2014b, p. 222.

${ }^{39}$ Ejemplificando con el modelo alemán, BECK, 2012, pp. 229 y 230. En este mismo sentido, HeNNING, 2014b, p. 222 y Hofmeister, 2014, p. 251, Henning, 2014a, p. 14.

${ }^{40}$ En este sentido, Miller, 2000, p. 3; Ferretti, 2013, pp. 794 ss.

41 SENENT, 2015 , pp. 5 y 7.

${ }^{42} \mathrm{El}$ art. 18 LPVP establece que luego de cinco años no podrán comunicarse los datos, pero no establece su eliminación de los registros. 
personales y su libre circulación ${ }^{43}$, como la LPVP $^{44}$, solo contemplan la posibilidad de que la propia persona inste la supresión de los datos en los casos que, por ejemplo, sean caducos o en que la fundamentación para su mantenimiento haya desaparecido, en lo que se denomina en el Reglamento como el derecho al olvido.

La justificación de lo anterior se encuentra en el derecho de autodeterminación informativa, que implica la posibilidad de controlar el flujo de información ${ }^{45}$ que a la persona concierne, tanto en la recolección como posterior tratamiento y uso de datos personales, mediante ciertos derechos subjetivos como el consentimiento, el derecho de acceso y de restricción ${ }^{46}$. Sin embargo, se ha señalado que la consideración del consumidor como un bomo oeconomicus ${ }^{47}$, sin tomar en consideración los problemas de analfabetismo o desconocimiento financiero, el sesgo del statu quo, problemas de autocontrol y el sobreoptimismo ${ }^{48}$, tienen como consecuencia el desconocimiento del derecho que tiene de disputar errores de información de forma gratuita ${ }^{49}$. La falta de plazo máximo y de una obligación eficaz para que el órgano que trata la información elimine registros negativos ${ }^{50}$, implica el mantenimiento por tiempo indeterminado de la información vinculada a un procedimiento concursal y a la descarga de la deuda, lo que limita indefinidamente el derecho al alivio del deudor. Efectivamente, la multa establecida en el art. 16, para el caso de incumplimiento del art. 19 inciso 3, es manifiestamente baja, y solo procede luego de haber sido instado un procedimiento por reclamación del afectado. En este contexto, se ha señalado que la razón para limitar el tiempo de conservación de información negativa está en impedir que la misma continúe perjudicando al afectado durante su vida o por un periodo excesivamente largo ${ }^{51}$.

Asimismo, respecto del contenido y como se ha constatado, mientras el BC mantiene disponible al público toda información vinculada al concurso, los registros emanados de la CMF contienen información de deudores respecto de quienes ha operado la descarga de la deuda residual.

En el modelo alemán, la anotación en el registro concursal solo incluye la denegación o revocación de la exoneración, motivada por circunstancias en que el deudor ha incurrido en una maliciosa o manifiestamente negligente infracción de un deber en

43 Artículo 17 del Reglamento (UE) 2016/679 del Parlamento Europeo y del Consejo, 2016.

${ }^{4}$ Art. 12 inciso 3 LPVP.

45 Ferretti, 2013, p. 811.

46 Rostión, 2015, p. 501; Contreras y Trigo, 2019, p. 71.

${ }^{47}$ Osovsky, 2013, pp. 884 y 899, plantea que el sistema actual prevé consumidores racionales, atentos y alertas. En igual sentido, Goldenberg, 2020, p. 7.

48 Problemas también tratados por Goldenberg, 2020, pp. 8 ss.

49 Osovsky, 2013, pp. 902, 905, 906, 910.

50 Álvarez, 2016, pp. 62 y 63, da cuenta de la falta de cumplimiento por las instituciones de los derechos consagrados en la LPVP, que solo ha regulado el tratamiento de datos y no un derecho efectivo de los titulares a tener control sobre los mismos, lo que se produce por la inexistencia de un ente fiscalizador, de un procedimiento administrativo efectivo de reclamo y la falta de sanciones eficaces y disuasivas. De igual forma, CAMACHO, 2014, p. 81.

51 Pascual, 2017, p. 163. 
detrimento de los intereses del procedimiento o de sus acreedores ${ }^{52}$. Por el contrario, el modelo nacional otorga un carácter negativo a la descarga de la deuda propiamente tal, al posibilitar el mantenimiento en un registro de una circunstancia que debe entenderse positiva para el deudor ${ }^{53}$. Respecto del tema, considérese que, desde el punto de vista de la regulación concursal de la persona natural, la descarga de la deuda es una herramienta que manifiesta el contenido del principio del fresh start y posibilita el logro de la finalidad del procedimiento concursal de persona natural, otorgar alivio al deudor $^{54}$, entendido como el retorno del deudor a condiciones que implican volver a ostentar la capacidad para desarrollar libremente su personalidad y lograr el desarrollo de su familia ${ }^{55}$.

El Mensaje del Proyecto de la Ley 20.720, criticando que las herramientas concursales existentes estaban dotadas "de una carga negativa que tiende a darle especialmente a la quiebra un tinte infamante que en definitiva dificulta en grado sumo al afectado su reinserción en la dinámica económica habitual", daba cuenta que la nueva regulación fomentaría el uso de términos y frases que incentivarían un tratamiento técnico a los intervinientes, "que no verían afectado ni su prestigio ni su honra por el hecho de acogerse a la legislación pertinente" ${ }^{56}$. Sin embargo, y de manera contraria, el registro del hecho del concurso o de la concesión de la descarga conlleva un trasfondo negativo ${ }^{57}$ para los deudores, quienes sienten el estigma social del fracaso, pues son caracterizados, sin distinción y por tiempo indefinido en caso del modelo nacional (al que se suma el tiempo transcurrido durante el procedimiento concursal), como deudores respecto de quienes, a pesar de lograr una descarga de la deuda, es preciso tener cuidado y respecto de quienes eventualmente sería riesgoso otorgar crédito ${ }^{58}$. En este contexto, respecto de la creación de perfiles a partir de la información recopilada, que pueden ser utilizados para causar un detrimento en la expectativa de una persona, se indica que la falta de control en el tratamiento de datos supone un peligro para los individuos 59 .

Un impedimento para el logro de alivio representa para la persona y su familia una contradicción entre los objetivos impuestos socialmente, y esperados particularmente por el individuo, y los mecanismos jurídicos que el ordenamiento pone a su disposición para alcanzarlos ${ }^{60}$. Constituyéndose el procedimiento concursal de la persona natural en mecanismo de ultima ratio para otorgar una solución definitiva al problema subyacente

52 Respecto de la denegación y revocación de la descarga, Alarcón, 2021b, pp. 323 ss. y 400 ss.

53 En este sentido, y para el caso español, Cuena, 2016, pp. 119 y 120.

54 Alarcón, 2021a, pp. 319 y 329.

55 Osovsky, 2013, p. 887, plantea que el supuesto de que el comportamiento pasado es un predictor relativamente preciso del comportamiento futuro entra en conflicto con la idea de que las personas deben tener la oportunidad de reconstruir su reputación después de contratiempos pasados.

56 Mensaje, Historia de la Ley 20.720, p. 10.

57 BECK, 2012, p. 228.

58 En el modelo español, concuerda Cuena, 2016, p. 68; Cuena, 2017, pp. 295 y 297.

59 Pascual, 2017, p. 139.

${ }^{60}$ García-Pablos, 2014, pp. 790 y 791. 
de la insolvencia de la persona natural ${ }^{61}$, que el mismo procedimiento imposibilite el logro de un real alivio impide el retorno del deudor a las circunstancias de vida que le permitan alcanzar un libre desarrollo de su personalidad y el de su desarrollo familiar, por tanto, alcanzar una vida digna ${ }^{62}$.

La discrepancia entre los objetivos perseguidos por el deudor en el procedimiento concursal y la ineptitud de los medios de que dispone para obtenerlos se traduce en un factor que genera tensión ${ }^{63}$ incremental, que a su turno, y como consecuencia de la aparición de reacciones de malestar social y ante una falta de mecanismos de contención sociales y jurídicos ${ }^{64}$, podrían derivar en la generación de conductas desviadas ${ }^{65}$ o actos delictivos por parte de algunos individuos para afrontar el conflicto generado ${ }^{66}$.

Considerando las fuentes de la tensión, a saber, la imposibilidad de alcanzar objetivos sociales positivos, la privación de gratificaciones que un individuo ya posee, espera poseer o que poseía ${ }^{67}$, y el sometimiento a situaciones negativas o adversas de las que no puede escapar ${ }^{68}$, cada una se encuentran presentes en el deudor que, teniendo una situación de vida específica (que no necesariamente es sinónimo de buena) o en espera de una situación de vida que podemos catalogar como digna de acuerdo con cánones sociales y culturales, es sometido de manera inevitable a largos años de estigmatización, con una consecuente falta de desarrollo personal y familiar.

El carácter restrictivo que otorga a los procedimientos concursales la regulación de las anotaciones de la descarga en registros de deudores es manifestación de una percepción negativa de la persona natural insolvente. Siguiendo a alguna doctrina alemana ${ }^{69}$, la visión que tendría el legislador a la hora de establecer tales reglas es la de un deudor despreocupado, negligente o imprudente, responsable de su situación de insolvencia. De allí que ciertos elementos característicos de la regulación concursal de la persona natural (como el tratado) se presenten restrictivos o privativos del interés del deudor por obtener un alivio efectivo ${ }^{70}$.

Desde estas consideraciones, la configuración de un sistema concursal destinado a tratar el problema de la insolvencia se construye a partir de una caracterización o

${ }^{61}$ Aunque no de manera expresa, se puede inferir de lo señalado por Hergenröeder y HomanN, 2013 , p. 129.

${ }^{62}$ Sobre el punto, Alarcón, 2021a, p. 338. En este contexto, Beck, 2012, p. 232.

63 Giddens, 1998, p. 740.

${ }^{64}$ Como pudiera ser una asesoría integral, social y continua de la deuda. Acerca del tema, AlARCón, 2021 b, pp. 174 ss.

65 STEPHAN, 2012, p. 88.

${ }^{66}$ Garrido et al., 2006, p. 233.

${ }^{67}$ Mayores detalles en GARRIDO et al., 2006, p. 241..

68 GARrido et al., 2006, p. 241.

${ }^{69}$ BECK, 2012, pp. 226 y 228.

${ }^{70}$ Lo mismo sucede con el establecimiento de un periodo de buena conducta o Woblverhaltensperiode; excepciones, motivos de denegación o causales de revocación de la descarga de la deuda injustificadas. Para una mayor comprensión, Alarcón, 2018, pp. 19 a 28; Caballero, 2018, pp. 158 y ss.; Alarcón, 2020, pp. 205 y ss.; Alarcón, 2021b, pp. 418 ss. y 445 ss. 
etiqueta dada a los deudores personas naturales ${ }^{71}$. A partir de las consideraciones de la teoría del etiquetado o labeling, la situación de insolvencia, entendida con una connotación negativa, significa para el deudor ser considerado como un individuo que ha actuado de manera errónea, imprudente, negligentemente o desviada ${ }^{72}$, lo que justifica la configuración de un procedimiento concursal, o sistema de control y tratamiento ${ }^{73}$, con un carácter represivo.

Ahora bien, el etiquetaje no solo afecta la forma en que un individuo es visto por los demás, sino que también influye en la idea que tiene de sí mismo ${ }^{74}$, aceptando la etiqueta y convirtiéndola en algo esencial para su identidad personal, posibilitando que el comportamiento desviado continúe o se intensifique ${ }^{75}$. El sometimiento del deudor a un contexto de estigmatización y escasez por largo tiempo, por tanto, la imposición de un contexto de privación de un real retorno a las circunstancias de vida que le permitan un desarrollo personal y familiar, influye en el reforzamiento de su autoconcepto de desviado, que facilita o posibilita una tendencia a la marginación y repetición de la conducta no querida $^{76}$, esto es, economía sumergida ${ }^{77}$, situaciones de nueva insolvencia con probabilidad de asunción de deuda de manera irreflexiva o irresponsable, o en caso de acumulación de gran tensión, a situaciones delictuales de menor o mayor connotación ${ }^{78}$.

\section{Disipando CONFUSIONES, PARA UNA ARMONIZACIÓN DE LA NORMATIVA}

La LPVP posibilita la recolección de datos de carácter económico, financiero, bancario o comercial, incluyendo en esta categoría los datos patrimoniales negativos, como son los referidos a insolvencia, mora y protestos ${ }^{79}$, cuando provengan de fuentes accesibles al público, sin el consentimiento de la persona ${ }^{80}$. Desde el punto de vista del interés legíti-

${ }^{71}$ Según GARRIDO et al., 2006, p. 394, “[...] los mecanismos de aprender a ser desviado [...] suelen ser consumados por las propias instituciones que supuestamente tienen la finalidad de erradicar la desviación [...]”. De lo señalado por GARcía-PABlos, 2014, p. 861, el carácter desviado de una conducta y su autor depende de ciertos procesos sociales de definición, que atribuyen a la misma tal carácter, y de selección, que etiquetan al autor como desviado.

72 De acuerdo con GidDens, 1998, p. 743, "según Becker, el 'comportamiento desviado es aquel al que la gente cuelga esa etiqueta'”.

73 En este sentido, Garrido et al., 2006, p. 391.

${ }^{74}$ GidDENS, 1998, p. 744.

75 Giddens, 1998, p. 744.). García-Pablos, 2014, pp. 860 a 862. Garrido et al., 2006, p. 392.

76 Bernburg y Krohn, 2003, p. 1289. En el modelo alemán, Pape, 2012, p. 153, expresa que bajo la etiqueta de "mayor fortalecimiento de los derechos de los acreedores" se regulan nuevas reglamentaciones psicológicamente muy perjudiciales.

${ }^{77}$ En este sentido, BECK, 2012, p. 232.

${ }^{78}$ Dick, 2007, p. 126, da cuenta de la posible relación entre el sobreendeudamiento y la comisión de delitos. De igual forma, relacionando una falta de acceso al crédito con eventuales situaciones de ilegalidad, GoldenberG, 2020, p. 12.

79 SANZ, 2013, p. 474.

${ }^{80}$ Art. 4 LPVP 
mo ${ }^{81}$ que justifica esta regulación, el inciso segundo del art. 14 LGB plantea que "Con el objeto exclusivo de permitir una evaluación habitual de las instituciones fiscalizadas en virtud de la presente ley por firmas especializadas que demuestren un interés legítimo”, la CMF deberá darles a conocer la nómina de deudores de tales entidades, los saldos de sus obligaciones y las garantías que hayan constituido. Aunque el párrafo primero del punto 2 del Capítulo 18-5 RAN plantea que contraviene la intención del legislador incluir en un registro oficial de deudores información de personas respecto de quienes no aparece demostrado interés en exigírseles el cumplimiento de sus obligaciones eficazmente, o de aquellas cuya condición de deudores no se encuentre establecida de un modo formalmente incuestionable, la justificación del establecimiento del registro no radica en la protección del consumidor, sino en la protección del interés de los acreedores, en la medida que la información posibilita valorar las aptitudes del deudor para cumplir obligaciones que eventualmente surjan con el otorgamiento de crédito ${ }^{82}$. Detrás de esta comprensión se encuentra el objetivo de favorecer una evaluación de la solvencia del deudor a efectos de conceder crédito ${ }^{83}$ y resguardar el mercado del crédito ${ }^{84}$.

Pero lo cierto es que la fórmula nacional en apartados anteriores descrita nada aporta al acreedor para valorar la solvencia actual del deudor, pues solo recibe información que le permitirá observar que en algún momento fue insolvente, no cumplió sus obligaciones, o que estuvo inmerso en un procedimiento concursal ${ }^{85}$. Además, considerando que el modelo nacional no distingue si el deudor cayó en insolvencia mediando buena o mala fe contractual, o si la descarga de la deuda fue otorgada a un deudor de buena o mala conducta procedimental $^{86}$, se tiene que el hecho de la insolvencia, el haber sido deudor concursado, o el haber obtenido la descarga, a la vista del acreedor son apreciados de manera negativa. Pero esta apreciación no se relaciona con una objetiva valoración de la conducta de pago del deudor de cara a un nuevo crédito, sino que es subjetiva, que caracteriza a todo deudor sin distinguir si la insolvencia se debió a una conducta negligente o a circunstancias imprevisibles ${ }^{87}$.

Como límite al tratamiento de datos en interés legítimo del responsable se encuentra el interés del titular, en la medida que un test de ponderación, en el que se preste atención al impacto de cualquier posible consecuencia del tratamiento, su forma, expectativas razonables del titular o el estatus del responsable y del titular, permita

${ }^{81}$ Acerca del interés legítimo como justificación para el tratamiento de datos personales, dando cuenta de su plasmación en la LGB, Contreras y Trigo, 2019, pp. 74 ss. y 98.

${ }^{82}$ De la justificación de entrega de información del prestatario para evaluar el riesgo financiero, Miller, 2000, p. 3.

${ }^{83}$ Corroborado por el art. 1 Ley 20.575, 2012.

${ }^{84}$ Rostión, 2015, p. 500; Cuena, 2017, p. 287.

${ }^{85}$ En este sentido, Turner y Varghese, 2010, p. 7.

${ }^{86}$ Alarcón, 2018, p. 34 ss.; Caballero, 2018, p. 162.

${ }^{87}$ Respecto del sobreendeudamiento activo y pasivo, Alarcón, 2018, pp. 28 ss.; Caballero, 2018, p. 137; Bozzo, 2020, p. 164. 
determinar la prevalencia de los derechos de este ${ }^{88}$. Con esta base, entendemos que el derecho al efectivo alivio se constituye en un interés legítimo del exdeudor (titular de los datos), que justifica la exigencia de reglas adicionales para evitar la afectación del derecho del consumidor.

Ahora bien, medidas que permitan prevenir el sobreendeudamiento y posterior insolvencia de las personas naturales deben considerar una evaluación de la solvencia del futuro deudor por el prestamista ${ }^{89}$. En este contexto, el impacto de estas medidas preventivas a partir de la actividad del mercado del crédito ${ }^{90}$ se vincula estrechamente con la información crediticia de las personas naturales a la que pueden acceder los prestamistas para evaluar el riesgo crediticio $^{91}$. Si bien el tema de la evaluación de la solvencia se ha abordado en otros trabajados ${ }^{92}$, por espacio y atendido al objetivo del presente, me referiré brevemente a los registros de solvencia positivos ${ }^{93}$ como herramienta para valorar la solvencia del futuro deudor ${ }^{94}$.

Los sistemas de información crediticia son registros o bases de datos que suministran información respecto de la conducta crediticia de una persona ${ }^{95}$, por medio de la reunión de datos financieros de consumidores por terceros que los recopilan, procesan y transfieren a prestamistas para valorar su confiabilidad financiera ${ }^{96}$. A diferencia de los registros de solvencia negativos, que consideran los incumplimientos de una persona, los registros positivos consideran los recursos con los que cuenta, nivel de endeudamiento y capacidad de pago que presenta y su comportamiento de cumplimiento de obligaciones $^{97}$. En nuestro país, en el ámbito privado, el Informe Dicom Platinum 360 Equifax, en el ítem de comportamiento financiero, solo contiene información relativa a impagos, morosidades y protestos. Por su parte, en el ámbito público ${ }^{98}$, por aplicación del art. 14 LGB complementado por el Capítulo 18-5 RAN, la información enviada por bancos e instituciones financieras a la CMF contiene datos de deudas de cualquier

${ }^{88}$ Explicando con detalle el punto, Contreras, 2019, pp. 79 ss.

${ }^{89}$ De igual manera, GoldenberG, 2020, p. 15; Bozzo, 2020, p. 176.

90 Si bien existen diversas causas del sobreendeudamiento del consumidor, una constatada son las prácticas blandas o irresponsables de otorgamiento de crédito. Así, Ruz, 2017, p. 502; Bozzo, 2020, p. 164; Alarcón, 2021c, en prensa.

91 Anidjar y Mizrahi-Borohovich, 2020, p. 180; Cuena, 2014, p. 2. En contra y planteando otras prioridades, FERRETTI, 2013 , pp. 815 y 816.

92 Por todos, Alarcón, 2021c, en prensa.

93 Sobre su impacto para la noción de crédito responsable y las consecuencias de los registros negativos, Cuena, 2011, pp. 43 y ss.; Cuena, 2014, pp. 9 y ss.; Cuena, 2016, pp. 121 y 122.

94 Cuena, 2014, p. 9.

95 Pascual, 2017, p. 122, Cuena, 2017, p. 286, indica que introduce criterios cualitativos en la evaluación de solvencia.

${ }^{96}$ Anidjar y Mizrahi-Borohovich, 2020, p. 180. Sobre algunas justificaciones, Turner y Varghese, 2010, p. 5; Cuena, 2017, pp. 285 y 331.

97 Miller, 2000, p. 4; Cuena, 2014, p. 10; Pascual, 2017, pp. 149 y 150; Cuena, 2017, pp. 296 y 298; Bozzo, 2020, p. 174.

${ }^{98}$ Una descripción de registros crediticios públicos y privados en Miller, 2000, p. 10 y FerretTi, 2013, pp. 800 ss.; Pascual, 2017, p. 147. 
magnitud ${ }^{99}$, pero los cumplimientos solo son conocidos por la institución del cliente. Por su parte, el art. 9 inciso 3 LPVP incentiva el uso de datos negativos de cara a una valoración del riesgo comercial, al prohibir la realización predicciones o evaluaciones de riesgo comercial que "no estén basadas únicamente" en información objetiva relativa a morosidades o protestos de personas naturales de las que se informa.

Los registros crediticios positivos posibilitan que los acreedores valoren adecuadamente el riesgo financiero de sus futuros deudores, sin estigmatizar el incumplimiento ${ }^{100}$ y fomentando el cumplimiento ${ }^{101}$; permitiendo distinguir entre deudores sin impagos y deudores solventes ${ }^{102}$, debido a que brindan una imagen de la solvencia donde figura el historial de cumplimiento, uso de tarjetas de crédito sin incidencias y niveles de endeudamiento global del consumidor ${ }^{103}$. Desde esta consideración, la finalidad de protección del interés de pago de los prestamistas es cumplida por un sistema de información que considera la conducta de cumplimiento del consumidor y que permite valorarla objetivamente ${ }^{104}$ en una adecuada evaluación de solvencia ${ }^{105}$.

Los aspectos favorables de un sistema de información positiva son: disminución de posibilidades de selección adversa, esto es, otorgar crédito a quien en principio parece merecerlo cuando en realidad no es así, o denegación o adecuación de un crédito a quien se lo merece, lo que aumenta el acceso al crédito ajustado para segmentos sociales más necesitados ${ }^{106}$; evita situaciones de riesgo moral $^{107}$; permite que el prestamista pueda hacer una oferta de crédito adecuada a la situación particular del futuro cliente, impidiendo que los riesgos de la concesión del crédito sean trasladados a otros prestatarios mediante el aumento del costo ${ }^{108}$; favorece la predisposición del prestamista a renegociar los términos del contrato ${ }^{109}$; finalmente, posibilita un mayor control del sistema financiero y facilita la exigencia de responsabilidad por concesión abusiva de crédito $^{110}$, ya que el método entrega criterios para la concesión de crédito de manera responsable ${ }^{111}$.

${ }^{99}$ Miller, 2000, pp. 11 a 13, explica que una mayor cantidad de datos complica la gestión, registro y el análisis, siendo probable que los datos de préstamos pequeños incluyan errores, que reduce la calidad general de la información registrada; lo que perjudicaría al deudor.

${ }^{100}$ Bozzo, 2020, p. 175, considera que los ficheros de solvencia negativos estigmatizan al deudor que por circunstancias imprevisibles incumple.

101 En este sentido, Pascual, 2017, p. 127.

102 Cuena, 2017, p. 296.

103 Cuena, 2014, p. 10.

${ }^{104}$ De la necesidad de objetividad, Goldenberg, 2020, p. 16.

105 En este sentido, Cuena, 2011, pp. 36.

106 Cuena, 2017, p. 310; Anidjar y Mizrahi-Borohovich, 2020, p. 182; Turner y Varghese, 2010 , p. 19, aportando antecedentes para la apertura del crédito a grupos con ingresos bajos, minorías étnicas, jóvenes y mujeres.

107 Turner y VArghese, 2010, p. 22.

108 Anidjar y Mizrahi-Borohovich, 2020, p. 181. De la disminución de tasas de interés promedio, Turner y VARGHese, 2010, pp. 22 y ss.

109 Anidjar y Mizrahi-Borohovich, 2020, p. 183.

${ }^{110}$ Cuena, 2014, p. 12.

111 Anidjar y Mizrahi-Borohovich, 2020, p. 182. 
Frente a la idea de los registros positivos, y cumpliendo también una función preventiva de conductas abusivas de parte de deudores, surge la necesidad de contar con información que determine su buen comportamiento desde el punto de vista del cumplimiento de obligaciones. A partir de ello, y en el ámbito concursal, considerando la disparidad de tipos de deudores existentes ${ }^{112}$ y que la insolvencia de las personas naturales no se produce necesariamente por un sobreendeudamiento activo o una mala fe contractual ${ }^{113}$, se requiere una diferenciación que permita apreciar casos en que los deudores, a pesar del incumplimiento, no tienen culpa en su estado de insolvencia. Así, si se pretende incorporar a los registros circunstancias que objetivamente den cuenta de una conducta reprochable del deudor concursado, debe considerarse que, como en el modelo alemán, circunstancias en las que el deudor no ha podido ingresar al procedimiento, o en que la descarga ha sido denegada o revocada, dicen relación con una efectiva mala conducta previa al procedimiento concursal (mala fe contractual), o una mala conducta durante el procedimiento concursal o en un tiempo determinado con posterioridad al mismo (mala conducta procedimental). Solo estos casos, constatados fácilmente por el juez del concurso, justificarían su inclusión en registros de solvencia en que exista información negativa como positiva.

Lo anterior, sin embargo, requiere de una adecuada regulación legal de la buena fe contractual y buena conducta procedimental en el procedimiento concursal, cuestión respecto de la que si bien nuestra legislación se encuentra en deuda ${ }^{114}$, debe trabajarse con miras al cumplimiento de la finalidad del procedimiento concursal de la persona natural, otorgar un efectivo alivio al deudor ${ }^{115}$. De igual forma, por contribuir a este fin, y aunque no es el objetivo del presente trabajo, la vinculación entre la utilización de información crediticia del deudor y el derecho a la privacidad, exige una regulación protectora del consumidor respecto del tratamiento de información por organismos públicos y privados, por medio de una obligación de informarles su inclusión en registros en caso de que ello proceda con fundamento en el interés legítimo, concretándose los límites del uso de la información en relación con una expresa finalidad y estableciéndose plazos obligatorios de expiración de los datos ${ }^{116}$.

112 Goldenberg, 2017, pp. 70 ss..; Alarcón, 2021b, pp. 122 ss. y 148 ss.

113 Stephan, 2012, p. 86; Alarcón, 2018, p. 17; Caballero, 2018, p. 137; Goldenberg, 2020, pp. 3 y 11 ; RuZ, 2017, pp. 487 y 488.

${ }^{114}$ En este sentido, Caballero, 2018, p. 162; Alarcón, 2018, p. 10 ss.

115 De la buena fe en el procedimiento concursal de persona natural, AlarCón, 2021b, pp. 315 ss.

116 Turner y Varghese, 2010, p. 28. 


\section{CONCLUSIONES}

A nivel nacional se constata la existencia de registros de deudores que son o han sido parte en un procedimiento concursal, que perjudican el interés del deudor de lograr un efectivo alivio. Por un lado, el Boletín Concursal actúa como un tácito registro público de deudores en concurso y, por otro, la información de deudas de personas naturales recolectada por las instituciones financieras y tratada por la CMF contiene información caduca, al mantener entre sus datos deudas descargadas en el concurso. Ambos registros permiten al acreedor caracterizar negativamente y de forma subjetiva a los consumidores de cara al otorgamiento de un nuevo crédito. Luego, la normativa de protección de datos no contiene mecanismos de protección adecuados para deudores que han sido parte en un procedimiento concursal, para limitar el mantenimiento de información por las entidades financieras, relativa a su concurso, a la descarga o deudas descargadas.

A pesar de haber concluido satisfactoriamente el concurso, el mantenimiento de información por tiempo indefinido, y la introducción y posterior utilización de información caduca en los registros, limita el derecho al alivio de los deudores que, tras el procedimiento, esperan obtener el anhelado nuevo comienzo.

Ante los problemas del modelo nacional y la necesidad de resguardar el interés del acreedor frente al riesgo de incumplimiento, se requiere reconocer el subyacente interés del deudor persona natural por un nuevo comienzo y un reequilibrio de ambos mediante mecanismos que los promuevan. El objetivo del registro de deudores con información del concurso es posible de lograr con un registro crediticio que contenga información positiva, que permita al acreedor evaluar el riesgo crediticio, pero valorando elementos objetivos de cumplimiento del consumidor. Ello incentivaría una desestigmatización de la insolvencia y el incumplimiento, fomentaría una valoración adecuada de la solvencia del deudor, incentivaría la cultura de pago y una concesión responsable del crédito; lo que en definitiva promovería el logro de un efectivo alivio para la persona natural.

\section{BIBLIOGRAFÍA}

Alarcón, Miguel, 2018: "La deuda por obligación constituida a través de crédito con aval del estado no constituye excepción al discharge en el ordenamiento jurídico chileno", Revista Chilena de Derecho Privado, $\mathrm{N}^{\circ} 31$.

Alarcón, Miguel, 2020: "La naturaleza del periodo de buena conducta en el concurso de la persona física”, Anuario de Derecho Concursal, No 50.

Alarcón, Miguel, 2021a, "El principio del fresh start como exigencia normativa derivada de la dignidad humana”, Doxa, Cuadernos de Filosofía y Derecho, No 44.

Alarcón, Miguel, 2021b: El concurso de la persona natural. Cuestiones dogmáticas, Valencia: Editorial Tirant lo Blanch.

Alarcón, Miguel, 2021c: "El deber de evaluación de la solvencia del deudor persona natural por el prestamista y su necesaria implementación en el ordenamiento jurídico chileno. Propuesta interpretativa para su reconocimiento", en Isler, Erika (directora), GPS de Derecho de Consumo, Editorial Tirant lo Blanch, en prensa. 
Alvarado, Francisco, 2014: "Las fuentes de acceso público a datos personales", Revista Chilena de Derecho y Tecnología, Vol. 3, No 2 .

Álvarez, Daniel, 2016: "acceso a la información pública y protección de datos personales. ¿puede el consejo para la transparencia ser la autoridad de control en materia de protección de datos?", Revista de Derecho UCN, Año 23, No 1.

ANIDJAR, Leon y Mizrahi-Borohovich, Inbar (2020) "Reinventing credit data sharing regulation", Southern California Interdisciplinary Law Journal, Vol. 9, № 2.

Baeza, Gonzalo, 2013: Derecho Concursal Chileno, Tomo II, Santiago: Thomson Reuters.

BECK, Frank, 2012: "Der Referentenentwurf zur Reform des Insolvenzrechts vom 18.1.2012 aus Schuldnerperspektive”, ZVI - Zeitschrift für Verbraucher- und Privat-Insolvenzrecht, Heft 6

Bernburg, Jon y Krohn, Marvin, 2003: "Labeling, life chances, and adult crime: the direct and indirect effects of official intervention In adolescence on crime In early adulthood", Criminology, $\mathrm{N}^{\circ} 41$.

Bozzo, Sebastián, 2020: "Sobreendeudamiento del consumidor en Chile: una revisión a la luz del derecho europeo", Revista de Derecho (Valdivia), Vol. XXXIII, Nº 1.

Caballero, Guillermo, 2018: "Sobreendeudamiento y exoneración legal de los saldos insolutos en el procedimiento concursal del consumidor", Ius et Praxis, Vol. 24, $\mathrm{N}^{\circ} 3$.

Camacho, Gladys, 2014: "La protección de datos como frontera del derecho de acceso a la información en la legislación chilena”, Revista de Gestión Pública, Vol. III, Nº 1.

Contreras, Pablo y Trigo, Pablo, 2019: "Interés legítimo y tratamiento de datos personales: antecedentes comparados y regulación en Chile", Revista Chilena de Derecho y Tecnología, Vol. $8, \mathrm{~N}^{\circ} 1$.

Cuena, Matilde, 2011: "Fresh start y mercado crediticio", InDret, $\mathrm{N}^{\circ} 3$.

Cuena, Matilde, 2014: "Préstamo responsable, información crediticia y protección de datos personales”, Revista de Derecho Concursal y Paraconcursal, N² 20, Editorial Wolter Kluwer (Smarteca).

Cuena, Matilde, 2016: "La exoneración del pasivo insatisfecho", en Prats, Lorenzo (coordinador), Comentarios a la Ley de Mecanismo de Segunda Oportunidad, Navarra: Editorial Thomson Reuters Aranzadi.

Cuena, Matilde, 2017: "Ficheros positivos de solvencia, privacidad y mercado de crédito", en Cuena, Matilde (directora) La prevención del sobreendeudamiento privado. Hacia un préstamo y consumo responsables, Navarra: Editorial Thomson Reuters Aranzadi.

Dick, Judith, 2007: "Versagungsgründe - aktuelle Rechtslage und Neuregelung durch den Referentenentwurf 2007”, ZVI - Zeitschrift für Verbraucher- und Privat-Insolvenzrecht, Heft 3.

Ferrettri, Federico, 2013: "The Legal Framework of Consumer Credit Bureaus and Credit Scoring in the European Union: Pitfalls and Challenges - Overindebtedness, Responsible Lending, Market Integration, and Fundamental Rights", Suffolk University Law Review, Vol. XLVI, Nº 3 .

García-Pablos, Antonio, 2014: Tratado de criminología, (5ª edición), Valencia: Editorial Tirant lo Blanch.

Garrido, V., Stangeland, P. y Redondo, S., 2006: Principios de criminología, Valencia: Editorial Tirant lo Blanc.

Giddens, Anthony, 1998: Sociología, Madrid: Editorial Alianza.

Goldenberg, Juan Luis, 2017: "El necesario ajuste de la asignación del riesgo de sobreendeudamiento en la regulación de las tarjetas de crédito: desde un sistema basado en los deberes de información a un modelo de corresponsabilidad", Revista de Derecho PUCV, XLIX, No 2.

GoldenberG, Juan Luis, 2020: "El sobreendeudamiento y los paradigmas del consumidor financiero responsable y del proveedor financiero profesional”, Ius et Praxis, Vol. 26, No 1. 
Henning, Kai, 2014a: "Die Änderungen in den Verfahren der natürlichen Personen durch die Reform 2014", en ZVI - Zeitschrift für Verbraucher- und Privat-Insolvenzrecht, Heft 1.

Henning, Kai, 2014b: "Die Verkürzung des Restschuldbefreiungsverfahrens gem. $§ 300$ InsO n.F. - aus Schuldnersicht”, ZVI - Zeitschrift für Verbraucher- und Privat-Insolvenzrecht, Heft 6.

Hergenröeder, Curt y Homann, Carsten, 2013: "Die Reform der Verbraucherentschuldung: Plädoyer für eine Neuorientierung”, ZVI - Zeitschrift für Verbraucher- und Privat-Insolvenzrecht, Heft 4.

Hofmeister, Klaus, 2014: "Insolvenzrechtsreform 2014: Kein Hinkelstein, aber jede Menge Schotter im Detail”, ZVI - Zeitschrift für Verbraucher- und Privat-Insolvenzrecht, Heft 6.

Howard, Margaret, 1987: "A theory of discharge in consumer bankruptcy", Ohio State Law Journal, Vol. 48, No 4.

Informe Dicom Platinum 360 de Equifax. Disponible en: https://sec.equifax.cl/compraonline/ pdf/muestra_informe_dicom_platinum_360.pdf

Leturia, Francisco, 2018: "La publicidad procesal y el derecho a la información frente a asuntos judiciales. Análisis general realizado desde la doctrina y jurisprudencia española”, Revista Chilena de Derecho, Vol. 45, No 3 .

Miller, Margaret, 2000: Credit reporting systems around the globe: the state of the art in public and private credit registries. Disponible en: https://development-data-hub-s3-public.s3.amazonaws. com/ddhfiles/140745/credit_reporting_systems_around_the_globe_0.pdf

Osovsky, Adi, 2013: "The misconception of the consumer as a homo economicus: a behavioraleconomic approach to consumer protection in the credit-reporting system", Suffolk University Law Review, Vol. 46, No 3.

Pascual, Pablo, 2017: "Definición, funciones y estructura de los sistemas de información crediticia. El impacto del reglamento general de protección de datos de la Unión Europea", en Cuena, Matilde (directora) La prevención del sobreendeudamiento privado. Hacia un préstamo y consumo responsables, Navarra: Editorial Thomson Reuters Aranzadi.

PAPE, Gerhard, 2012: "Verbraucherinsolvenz 2012 - gefühlter und tatsächlicher Reformbedarf”, ZVI - Zeitschrift für Verbraucher- und Privat-Insolvenzrecht, Heft 4.

Pulgar, Juana, 2015: “Acuerdos extrajudiciales de pago, PYMES y mecanismos de segunda oportunidad”, Diario La Ley, No 8538 , Ref. D-188.

Rostión, Ignacio, 2015, "Sobre la Ley de Protección de la Vida Privada: La importancia de una "fuente legal” y su aplicación en las Personas Jurídicas", Ius et Praxis, Vol. 21, No 2.

Rubio, Pedro, 2016: "Segunda oportunidad o nueva oportunidad perdida en la Ley Concursal", Revista de Derecho Concursal y Paraconcursal, No 24, Editorial Wolter Kluwer (Smarteca).

Ruz, Gonzalo, 2017: Nuevo derecho concursal chileno, Tomo I, Santiago, Thomson Reuters.

SANZ, Francisco, 2013: "Solicitud de acceso a la información y tutela de los datos personales de un tercero", Revista de Derecho PUCV, XLI, $2^{\circ}$ semestre.

SCHMERBACH, Ulrich, 2012: "Änderungen in Insolvenzverfahren natürlicher Personen - Der Regierungsentwurf vom 18. 7. 2012”, VIA - Verbraucherinsolvenz aktuell, Heft 8.

SENENT, Santiago, 2015: "El nuevo régimen de exoneración de deudas tras el RDL 1/2015", Revista de Derecho Concursal y Paraconcursal, N²3, Editorial Wolter Wkuwer (Smarteca).

STEPHAN, Guido, 2012: "Stellungnahme zum Referentenentwurf eines Gesetzes zur Verkürzung des Restschuldbefreiungsverfahrens, zur Stärkung der Gläubigerrechte und zur Insolvenzfestigkeit von Lizenzen”, ZVI - Zeitschrift für Verbraucher- und Privat-Insolvenzrecht, Heft 3.

Turner, Michael y Varghese, Robin, 2010: "The economic consequences of consumer credit information sharing: efficiency, inclusion, and privacy", Background Paper $\mathrm{N}^{\circ} 2$, The Economics of Personal Data and Privacy: 30 Years after the OECD Privacy Guidelines. Disponible en: http://www.oecd.org/digital/ieconomy/46968830.pdf 


\section{Normas jurídicas citadas}

Capítulo 18-5 de Recopilación Actualizada de Normas de la SBIF, relativo a Información sobre deudores de las instituciones financieras.

Discusión en Sesión de Convalidación o Denegación del RDL 1/2015, Sesión Plenaria $\mathrm{N}^{\circ} 250$, Diario de Sesiones del Congreso de los Diputados, Pleno y Diputación Permanente, $\mathrm{N}^{\circ} 267$, año 2015.

Historia de la Ley $\mathrm{N}^{\circ} 20.720$, que sustituye el régimen concursal vigente por una ley de reorganización y liquidación de empresas y personas, y perfecciona el rol de la Superintendencia del ramo, Biblioteca del Congreso Nacional. Disponible en: http://www.bcn.cl/historiadelaley/ fileadmin/file_ley/4343/Pdf/Dossier/HLD_4343_dossier5674b2fe3b02aafa0af97e1d68f6efe6.pdf.

LEY 19.628, Protección de la vida privada, publicada el 28 de agosto de 1999.

LEY 20.575, Establece el principio de finalidad en el tratamiento de datos personales, publicada el 17 de febrero de 2012 .

LEY 20.720, Sustituye el régimen concursal vigente por una ley de Reorganización y Liquidación de Empresas y Personas, y perfecciona el rol de la Superintendencia del ramo, publicada el 09 de enero de 2014.

LEY 22/2003, de 09 de julio, Concursal. Boletín Oficial del Estado, núm. 164, de 10 de julio de 2003.

Proyecto de Ley de Reforma de la InsO de 2012, Del Gobierno federal para el acorTAMIENTO DEL PROCEDIMIENTO DE ALIVIO DE LA DEUDA Y FORTALECER LOS DERECHOS DE los acreedores, Deutscher Bundestag - Drucksache 17/11268, de 31 de octubre de 2012, BT-DruCKs. 17/11268.

Reglamento (UE) 2016/679 del Parlamento Europeo y del Consejo, 27 de abril de 2016, relativo a la protección de las personas físicas en lo que respecta al tratamiento de datos personales y a la libre circulación de estos datos y por el que se deroga la Directiva 95/46/ CE (Reglamento general de protección de datos).

\section{Jurisprudencia citada}

Corte de Apelaciones de Temuco, sentencia de 4 de mayo de 2018, rol 1.356-2018.

Corte Suprema, sentencia de 17 de diciembre de 2018, rol 15.516-2018.

Corte Suprema, sentencia de 30 mayo de 2018, rol 8.779-2018. 
